\title{
Online Module Technologies of Innovative Education Technologies of Educational Institutions of Pedagogical Education Programs
}

\author{
Rakhimova Surayyo Salohiddinovna \\ Department of "Methods of Preschool Education", Institute of Retraining and Improvement of Qualification, Uzbekistan
}

Received October 7, 2019; Revised December 8, 2019; Accepted December 11, 2019

Copyright $\mathrm{O} 2020$ by authors, all rights reserved. Authors agree that this article remains permanently open access under the terms of the Creative Commons Attribution License 4.0 International License

\begin{abstract}
In this article, you will be able to effectively use online modular technology to enhance the professional development of preschool teachers based on innovative educational technologies, retraining and advanced training of managers and specialists of preschool educational institutions in the context of modernization of education (МТМРПХМО) and their pedagogical and professional competence, potential and Defining modern pedagogical conditions for the level and quality of creativity; Defining ways to improve the effectiveness of innovative and didactic system of professional competence of executives and teachers in the information education environment, improvement of organizational methods and monitoring of educational process based on innovative technologies, content of education based on state content and quality of training and retraining of teachers. Ideas related to improvement are described in scientific theoretical terms. The article also examines the legal framework for reforming pre-school educational institutions.
\end{abstract}

Keyword Pedagogical Staff, Innovative Education, Creative Approach, Online Modular Technology, Social Environment, Computer Programs

\section{Introduction}

Special attention paid to pre-school education in the country in recent years and a number of documents adopted in this direction have allowed creating a legal framework for professional development of teachers. In the Decree of the President of the Republic of Uzbekistan "On Measures to Further Improve the System of Preschool Education in 2017-2021" ...... improvement of curricula and programs of training and advanced training of teachers in preschool educational institutions, taking into account modern pedagogical technologies and methods; introduction of modern educational programs and technologies in the educational process, comprehensive intellectual, moral, aesthetic and physical development of children. Is given in the form of continuing education in the school system of primary and recognized as a sign of particular importance in carrying out the tasks that need to pay attention to.

Creating an online modular technology to improve the МТМРПХМО system allows taking into account the competence of teachers, the state and society order, focused on the effectiveness of their activities, their personal, professional needs and training. Through the introduction of online modular technology, it is possible to effectively use best practices, to enhance the self-development of the teacher, to enhance self-education, as well as to maximize professional development, and to the use of innovative educational technologies.

It should be noted that the effectiveness of training in the system of advanced training based on innovative pedagogical technologies is achieved through the practical solution of the following tasks:

- Formation of an innovative educational process that takes into account the critical analysis of the activities of the trainees, the actual problems, controversies and needs of the trainees in determining the content of education based on the State Curriculum of the "First Step" Preschool ;

- Provision of integration of relevant disciplines, which envisage the purpose, principles, laws, teachings, activation of forms, methods and means of the organization of educational process, as well as innovative educational activities based on the specifics of the training of pedagogical staff of preschool educational institutions. Achieve priority;

- Providing the independence of listeners, the right choice of forms, methods and didactic means of designing, planning and training of technological and 
educational process, the formation of their motivation, ability to effectively solve pedagogical tasks, situations, to effectively plan the educational process creation of environment;

- $\quad$ Providing a favorable pedagogical and psychological climate for leaders and educators, allowing them to develop self-image, self-expression, mutual development and positive teaching experience;

- Development of skills of designing an individual educational trajectory, enhancing the motivation, mobility and reflexivity of the trainees;

- Use of game educational technologies, open borders of formal pedagogical communication, open discussion of mistakes and stimulation of creative activity in order to create favorable conditions for free choice of teachers and preschool teachers;

- Increasing attention to meta-competencies related to the effective organization of innovative teaching and administrative activities, the creation of new forms, methods and tools for teaching and training.

\section{Materials and Methods}

In the course of our research, we conclude that it is desirable to focus on the development of metacognitive competence, with the support of the core, private competence of educators to address the professional tasks of MTMPПХМOs based on innovative educational technologies.

In her research, Mirsolieva explains that "meta" (Greek, "meta" - between, and then) is the transition from certain processes to a new and different process or system. [5; ]

$\mathrm{N}$. Muslimov represents the concept of system - the unity of the orderly and interconnected parts, and the environment represents the metadata system of all systems. He explains that he lies outside the realm of the world that is being researched, isolated and at the same time surrounding us. [4;]

In the study of N. Muslimov, the system (the Greek system is a whole, composed of parts, connected together) refers to many elements that form a certain integrity, unity, interdependence and interdependence. If we explain the metacompetence of educators with a systematic approach to improving the content of teaching staff in preschools based on innovative educational technologies, it is a universal holistic typology of social, cognitive, functional competence that provides the effectiveness of professional activities and uses all professional competences. is considered a degree.

In particular, the teacher must design the appropriate requirements and strategies to the extent that the trainees demonstrate their abilities and skills in the learning process. The teacher should help his or her listeners deepen their knowledge, make the right amount and quality of knowledge required for them, and establish a free-creative learning environment to collaborate with listeners to test new knowledge and skills in different contexts and situations. This, in turn, will result from teacher:

- development and implementation of innovations, pedagogical technologies and didactic provision that promote the effectiveness of teaching on the basis of international experience;

- Free access to high-ranking international scientific-reference databases and publications;

- Implementation of direct, indirect, effective, multi-vector, multi-level MTMРПХMO systems

- development and implementation of scientific research to improve the professional skills and pedagogical skills of educators;

As we explore the best practices of using innovative pedagogical technologies to enhance teaching effectiveness based on national and international experience through open information systems, international emphasis is placed on the training, professional development and professional development of educators in developed countries. In our view, it is necessary to create conditions for their qualitative and continuous training in the MTMРПХМО process, including personal motivation, responsibility-based distance learning, online tutoring, tutorial training, multi-vector learning, independent learning and the introduction of activity-based forms.

According to the literature review and the Internet, in Australian education, employers are increasingly recruiting students who study online and in a mixed education system. One of the main reasons for this is that they are well versed in the use of computer technology and technology, as well as their ability to work and study independently.

As for the mixed education system, in the pedagogical literature, a mixed system of education is a combination of the system of distance learning with traditional education. At the same time, distance learning (e-learning) serves as a supporter of traditional education and enhances its capacity. During the experiment, we were convinced that through a mixed education system, the trainees will be able to access the distance education system, which includes training materials, test systems, online libraries, in all subjects taught during the professional development of preschool teachers. At the same time, part of the control of trainees' knowledge in a mixed system of education is obtained using online surveillance systems. Another important aspect is that students will have the opportunity to participate in various online projects. At the same time, the system of mixed education gives the students a great opportunity to master the subjects. In this learning process, not only do students have access to science materials online, they can also submit online test controls to determine their academic performance and receive additional information to improve them if they receive low marks. In addition, the distance learning system has elements such as forums, chat, and e-mail, so that students can interact with their 
classmates on specific issues, interact with science teachers, and get satisfactory answers to their teachers without waiting for the lecture.

In order to make the quality of education effective and interesting in the MTMPПХMO courses, the educator must be able to demonstrate his professional skills, work hard on it, and develop a motivation for consultation and innovation in the exchange of professional training.

At the same time, it is important to have modern teaching methods, advanced technologies, information and communication tools, research methods, diagnostic methods, the peculiarities of the organization of the educational environment, and the skills of designing, modeling, predicting the educational process.

The content of training sessions, pedagogical consultations, scientific and methodological observation should be focused not only on obtaining the necessary competencies, but also on the development of cognitive activity of the trainees and the development of ways of interaction with other subjects. It is important to use all the resources and capabilities of the system effectively, to ensure the full mobilization and engagement of the audience, and to take into account the challenges, needs, individual characteristics and levels of competence. [6;]

\section{Results and Discussion}

Continuous professional development of preschool leaders and educators prevails in professional training, motivated by a paradigm of interaction through information exchange, based on solidarity rather than competition, professional and personal growth. Vocational training is carried out gradually under the block-modular principles and incorporates a system of training that uses effective development techniques for organizational, methodological, information-analytical, predictive, diagnostic, and consultative methods [3; Page 34] Pedagogical counseling provides advisory support to the various subjects of education, as well as the organization of scientific and methodological supervision over the activities of the school and its staff [3; 35 pp.].

Moderation is an activity aimed at realizing the internal potential of educators. On the basis of moderation, special technologies are used to facilitate an atmosphere of free communication, exchange of ideas, and reasoning on the internal potential of the employee [3;35 pp.].

Supervision is based on systematic consultation of educators from experienced, specially trained colleagues who are in constant collaboration with the workplace, who understand, analyze and understand their professional behavior and behavior.

At the same time, the supervisor relies on the experience of the teacher as a facilitator and supervisor, which is formed during the course of designing the course of professional development and professional development.
The facilitation system represents the stimulus effect of pedagogical activity on the colleague's activities. It is based on respect for the personalities of the trainees and the right and freedom to choose the content of education. This process involves referring to the life and professional experience of the employee, facilitating the exchange of experience, and encouraging pedagogical skills.

During the experiment, we created and monitored the lecture materials and their presentation slides for distance learning, facilitating an easy and independent learning of the topic, for effective learning process. In the course of the workshop (face-to-face sessions) the participants discussed important and interesting topics of the course using innovative methods, strengthened practical knowledge and exchanged experiences between the participants.

It is positive that the textbooks and teaching aids are available in print and electronic form, making them easy, accessible and interesting for the audience by adding various multimedia applications to the electronic textbook. In fact, in the course of training and retraining, online communication is integrated into the mixed learning system with distance learning, such as chat, forums, e-mail, and it allows the audience to interact and work together. It also teaches you to work online, through personal and group online projects, to analyze data from different sources, as well as to work in small groups, that is, to distribute tasks in a group and to feel responsible for the work. Through such individual and group online projects, the trainees acquire the skills they need to work in a large audience.

By the way, working with listeners on the Internet through personal and group online projects, the names, number and types of centers based on the "First Step" and the Pre-Primary Education Program include the Building and Math Center, Center for Speech, Nature, the World and Literature, Center for Role-Playing and Dramatic Games, Age-Based Plot Games, Art Center, Painting, Applying, Clay, Building and Origami f The Center for Science and Nature has included activities to inform nature and the world. [2]We conclude that these elements of the blended learning system facilitate and enrich the learning process. The advantage of the blended learning system is the use of audio and video lectures, animations, and simulations. Within our observation, each element is dynamic, while the teacher is more active in the traditional system of education, while the more active in the system of blended education. This, in turn, ensures that students are more independent and have a better understanding of the meaning of science.

Each teacher introduces the audience to the important information that will be used in the course. The teacher, along with a list of required literature on the module, will provide the address of the course website, login and password for access to the course. The website also contains all the information you need for the course, study materials, and hyperlinks to access additional resources.

According to the foregoing, we can create a structure for 
improving the professional development of teachers of preschool educational institutions based on online modular technology. Training area for teachers of pre-school educational institutions: state and social order, purpose of training, implementation forms, master school, methodical service, traditional courses, attestation of supervisor and pedagogical staff, short courses, distance learning, improvement directions, educational content Improvement of modular technologies of formation, individualization and continuity of educational process, acmeological approach to the educational process.

Taking into account the requirements of the Pre-service Pedagogical Training Area, we focus on the benefits of improving online modular technology:

- information on all subject-related assignments, term of completion of assignments will be posted on the course site along with the schedule;

- $\quad$ as well as what tasks are recorded in the audience and which forums will be discussed. In the blended education system, the activity of the classroom is slightly diminished as some of the activities go online;

- The listener learns part of course material independently;

- Online activities are held in forums, chats or virtual audiences;

- $\quad$ Listeners will also be able to communicate via email with teachers and fellow students;

- Online activities are conducted in the form of questions and answers, or by discussing teacher-provided topics.

Askarov's research shows that a blended education system consists of two systems: traditional education and distance learning. He develops his ideas and acknowledges that it is desirable for a system of distance learning in a blended education system to be created in the MOODLE e-learning environment. Because the MOODLE e-learning system is currently available at all training facilities and its capacity meets all the requirements of the aforementioned elements for a blended education system and has a high reliability ratio. According to our scientists, it is possible to achieve a high efficiency through the development of a new theory of education related to changes in scientific and technical processes through the use of a blended system of education in the process of professional development.

\section{Conclusions}

In summary, education reform and scientific and technical progress require the creation of a system of high quality training through the use of new information technologies in the learning process. These requirements mean that the learning process should be organized with the use of new information technologies and based on it training of specialists who fully meet the educational standards.

\section{REFERENCES}

[1] Decree of the President of the Republic of Uzbekistan "On Measures to Further Improve the System of Preschool Education in 2017-2021" http://www.xs.uz/index.php/hom epage/rasmij/item/

[2] "First Step" State Curriculum T., 2018

[3] Scientific-methodical training of staff: pedagogical consultation and supervision / Pevzner, M. N. Pevznera, O. M. Zaishenko. - Veliky Novgorod: NovGU named after Yaroslava Mudrogo; Institute of Marketing and Staff Resources, 2002. - p.316.

[4] A. D. Askarov. Improving the System of Professional Development of Staff in Public Education in Distance Learning Mode: pedagogical sciences, $(\mathrm{PhD})$ abstract of dissertation. - Tashkent, 2017. -p. 51.

[5] Muslimov N.A. Theoretical-Methodological Bases of Professional Formation of the Teacher of Vocational Education: Ped.fanl.doc. ... diss. - T.: 2007. - p.357.

[6] M. T. Mirzolieva. Improvement of Mechanisms of Professional Competence of Managers and Teachers of Higher Educational Institutions. Ped.fanl.doc ... diss., - T .: 2019 p.357.

[7] A. A. Improvement of the system of training of the staff of public education on the basis of a multi-vector approach ... diss. , - T .: 2019143 b. 